\title{
Stress Analysis on Saw Blade of Hot Sawing Machine
}

\author{
Yinghua Xiang ${ }^{1,}$, Xiaoguang $\mathrm{Yu}^{1, \mathrm{~b}}$ \\ ${ }^{1}$ University of Science and Technology Liaoning, Anshan, Liaoning, PR China, 114051 \\ a yhxf726@sina.com, byuxiaoguang58@163.com
}

Keywords: Hot Sawing Machine, saw blade, FEM, four bar mechanism

\begin{abstract}
In this paper, static force analysis of saw blade before and after saw blade becoming thinner is done with FEM software connecting with the production practice of hot sawing machine. The intensity reliability theoretically after saw blade becoming thinner is proved. Polynomial regression for the equivalent stress on circular saw blades along radial direction were finished by the software MATLAB and different stress regression curve are got. Thereby, stress distribution law of whole saw blade was found. The result provides for theoretical basis for the further improvement of hot saw blade.
\end{abstract}

\section{Introduction}

Hot sawing machine is one of important equipments in hot rolling mill. The design level of hot Sawing Machine directly influence on the quality of section steel. A large section steel mill is one of important plants in our country, in which many large section steel and heavy rails are produced and the level of their main equipments have got the international level. The hot sawing machine is characterized by four bar mechanism. Circle saw blade contact directly with rolling work during sawing, the force and stress of saw blade are complex and saw frequently. The quality of saw blade has direct influence on the quality of steel. The further study on saw blade is very important. Therefore, FEM analysis of thick and thin saw blade is done with FEM software in this paper. The intensity reliability theoretically after saw blade becoming thinner is proved. Polynomial regression for the equivalent stress on circular saw blades along radial direction were finished by the software MATLAB and different stress regression curve are got. Thereby, stress distribution law of whole saw blade was found. The result provides for theoretical basis for the further improvement of hot saw blade.

\section{FEM analysis of thick and thin saw blade}

The service life while sawing with thin saw blade $(6 \mathrm{~mm})$ are not lower than thick ones and noise not higher when sawing $50 \mathrm{~kg} / \mathrm{m}$ heavy rails and $20 \#$ channel beam during production experimental study. Sawing power of thin saw blade is greatly lower than that of thick ones. Sawing power reduces $46.18 \%$ and $52.95 \%$ while sawing $50 \mathrm{~kg} / \mathrm{m}$ heavy rails and $20 \#$ channel beam. To customers of using saw blade, purchase saw blade Material cost is saved, smaller saw blades can be chosed and energy and equipment cost are all saved. In the meantime, the measured value of sawing power is similar with calculated value with the largest error $16.25 \%$ and much smaller than $10 \%$ which indicate that the calculated value of sawing power with theory equations is accurate. Moreover, there is not corner piece after sawing with thick saw blade when sawing $160 \times 100 \times 10 \mathrm{~mm}$ unequal angle steel and the phenomenon of head bent decrease too. Economic benefit of enterprise increase enormously. 
FEM is one of important method in calculate mechanics and one of Computer Aided Engineering (CAE). ANSYS is large software collecting structure, thermology, fluid, electromagnetic, acoustics. It's widely used in many industries for modeling simple, fast, and convenient and plays a large role in national economic constructing and science and technology developing.

In this paper, static force analysis of saw blade before and after saw blade becoming thinner is done with FEM software connecting with the production practice of hot sawing machine. The intensity reliability theoretically after saw blade becoming thinner is proved. Sketch map of saw blade model is shown in Fig. 1. The saw blade is divided into six sections named A, B, C, D, E, and F. Section A model is built and meshed. Other section models were generated along circumferential direction of saw blade with entity copy command. The whole Grid model of saw blade was got and shown in Fig. 2.
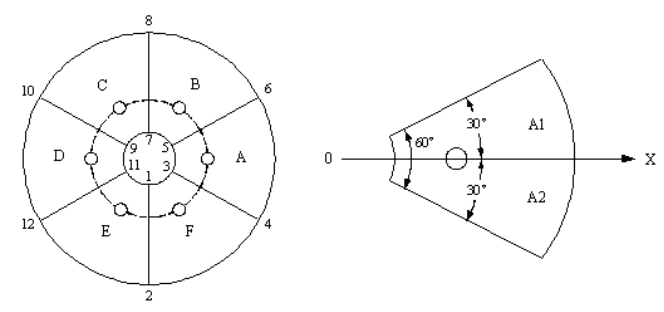

Fig. 1. Sketch map of saw blade model

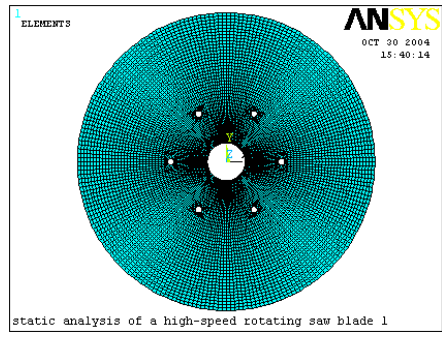

Fig. 2. Grid model of saw blade

Solve process is finished by exerting radial and circumferential direction displacement constrain and exerting radial and tangential concentrate load. The von Mises stress distribution of saw blade 1 is shown in Fig. 3 and Fig. 4 The von Mises stress distribution of saw blade 2, 3, 4 are shown in Fig. 5, Fig. 6 and Fig. 7. Analysis of saw blades is shown in Table 1.

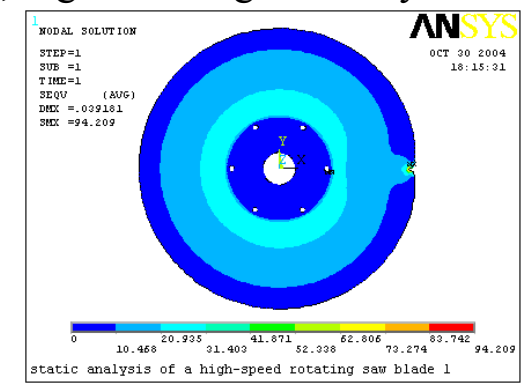

Fig. 3. The von Mises stress distribution of saw blade 1 under condition 1

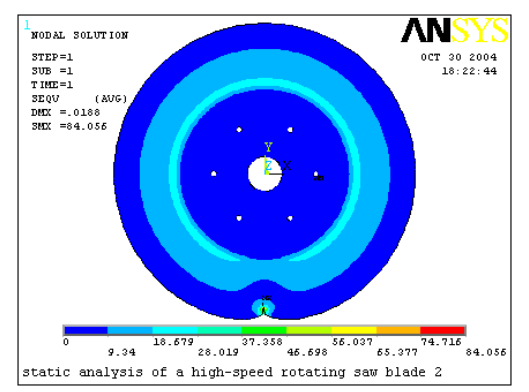

Fig. 5. The von Mises stress distribution of saw blade 2

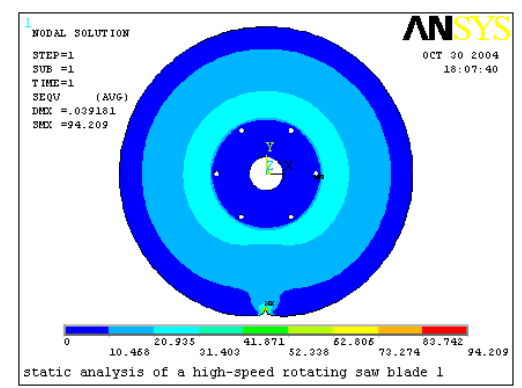

Fig. 4. The von Mises stress distribution of saw blade 1 under condition 2

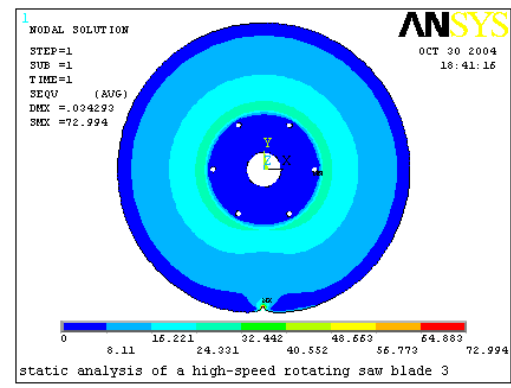

Fig. 6. The von Mises stress distribution of saw blade 3

The maximum deformation and maximum equivalent stress of saw blades can reduce by increasing reasonably the diameter of saw blades clip dish, increasing the ratio of D0/D and reducing the thickness of saw blade. The more the ratio of $\mathrm{D} 0 / \mathrm{D}$ increase, the more the ratio of deformation decrease and the more maximum equivalent stress decrease. 


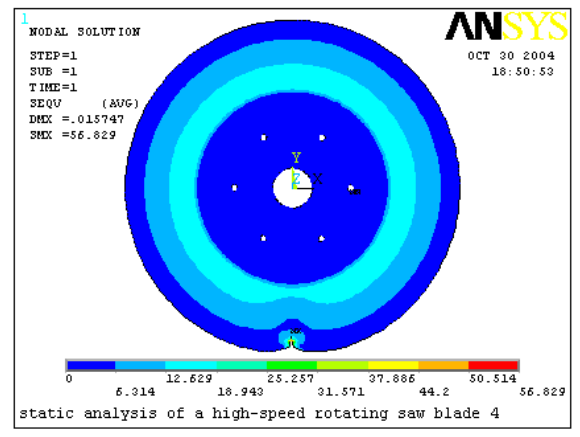

Fig. 7. The von Mises stress distribution of saw blade 4

Table .1. Analysis of saw blades

\begin{tabular}{ccccc}
\hline Number of saw blades & $1 \#$ & $2 \#$ & $3 \#$ & $4 \#$ \\
\hline $\mathrm{B}(\mathrm{mm})$ & 10 & 6 & 10 & 6 \\
Decrease ratio of B(\%) & 0 & 40 & 0 & 40 \\
$\mathrm{D}_{0} / \mathrm{D}(\%)$ & 0.426 & 0.638 & 0.437 & 0.656 \\
Increase ratio of $\mathrm{D}_{0} / \mathrm{D}(\%)$ & 0 & 49.77 & 0 & 50.11 \\
$\mathrm{DMX}(\mathrm{mm})$ & 0.039181 & 0.0188 & 0.034293 & 0.015747 \\
Decrease ratio of $\mathrm{DMX}(\%)$ & 0 & 52.02 & 0 & 54.08 \\
SMX $(\mathrm{MPa})$ & 94.209 & 84.056 & 72.994 & 56.829 \\
Decrease ratio of $\mathrm{SMX}(\%)$ & 0 & 10.78 & 0 & 22.15 \\
\hline
\end{tabular}

*DMX means maximum deformation of nodal points; SMX means maximum equivalent stress of nodal points; B means thickness of saw blade; D0/D means The ratio of external diameter of saw blades clip dish and external diameter of saw blades.

\section{Analytical investigation of equivalent stress distribution along radial direction of saw blade}

MATLAB is one of products of Math Works Company in USA. It's widely used in equation solution, Polynomial operations, Mathematics the extreme calculation, finance, industrial system simulation and statistics ${ }^{[6]}$. The function of polynomial fitting, calculate and the visualization of data and function of MATLAB are applied for discovering the equivalent stress distribution rule of saw blades. The equivalent stresses of circular saw blades are polynomial regressed along radial direction by using MATLAB software.

The results are that the stress distribution rule of thick and thin saw blades while sawing the same types of steel but the stresses of thin saw blades are smaller than those thick ones. Those results provide the basis for improving the saw blade of hot sawing machine. Graph of the von Mises stress distribution in No.1,2,3,4 saw blade are shown in Fig. 8, Fig. 9, Fig. 10, Fig. 11.

Those graphs indicate that the stress distribution rule of thick and thin saw blades while sawing the same types of steel $(50 \mathrm{~kg} / \mathrm{m}$ heavy rails and $20 \#$ channel beam) by comparing the stresses of No.1,2,3,4 saw blade but the stresses of thin saw blades are smaller than those thick ones about $10 \mathrm{MPa}$.

\section{Summary}

Production experimental study on thick and thin saw blades of hot saw machine is done in this paper. FEM analysis of saw blades is finished and the equivalent stresses of circular saw blades are polynomial regressed along radial direction by using MATLAB software. The main conclusions are as follows. 
(1)Thin saw blades has many advantages while applying in producing by means of study and analysis the production experimental results of hot sawing machine saw blades.

(2) FEM analysis of thick and thin saw blade is done with FEM software in this paper. The intensity reliability theoretically after saw blade becoming thinner is proved.

(3) Polynomial regression for the equivalent stress on circular saw blades along radial direction were finished by the software MATLAB and the stress distribution rule of thick and thin saw blades while sawing the same types of steel but the stresses of thin saw blades are smaller than those thick ones The result provides for theoretical basis for the further improvement of hot saw blade.

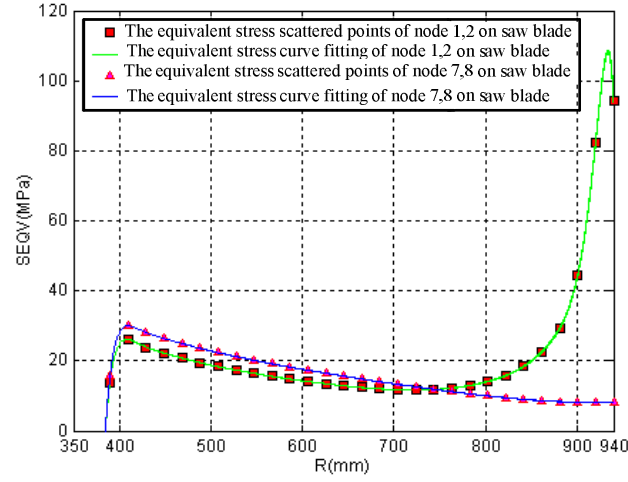

Fig. 8. Graph of the von Mises stress distribution in No.1 saw blade

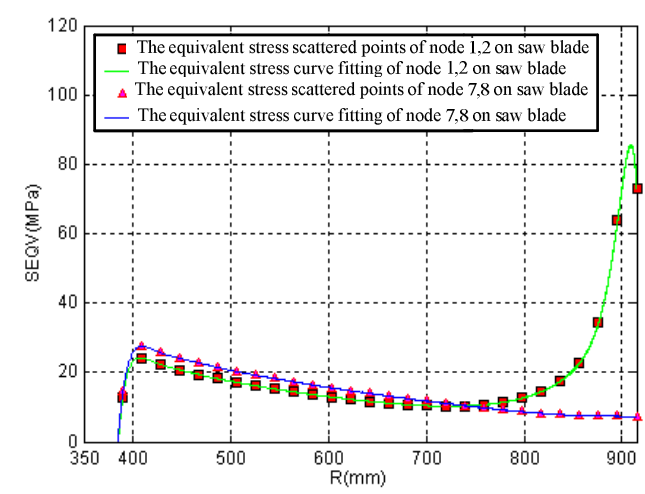

Fig. 10. Graph of the von Mises stress distribution in No.3 saw blade

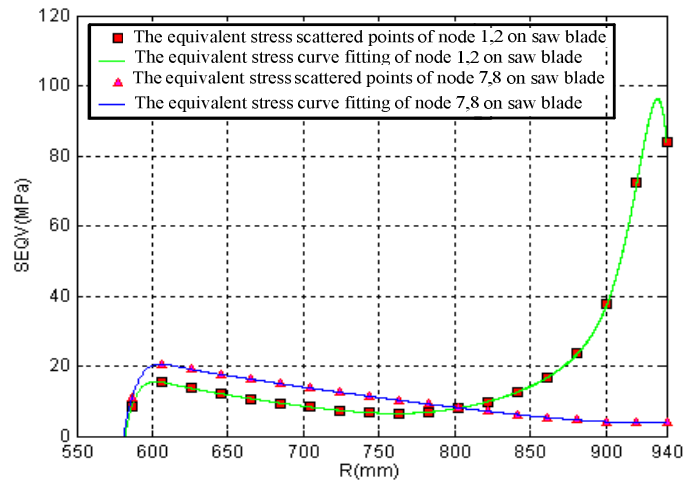

Fig. 9. Graph of the von Mises stress distribution in No.2 saw blade

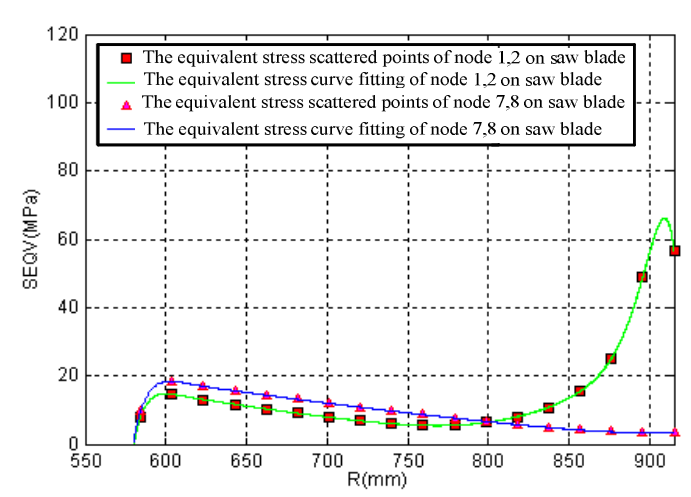

Fig. 11. Graph of the von Mises stress distribution in No.4 saw blade

\section{References}

[1] Zou Jiaxiang. Rolling machine(3rd Edition), Beijing: Metallurgical Industry Press, 2004, 333-340

[2] Li Tognjin, Zang Yong, et. Analysis on the Tooth Shape of the Saw Blade, JOURNAL OF UNIVERSITY OF SCIENCE AND TECHNOLOGY BEIJING, 2002, 24(1): 69-71

[3] Y Chen, X G Wang, C Sun, F Devine, C W De Silva. Active vibration control with state feedback in woodcutting[J], Journal of Vibration and Control, 2003, 9(6): 645

[4] Y.Xiang. Vibration of circular Mindlin plates with concentric elastic ring supports, International Journal of Mechanical Sciences, 2003, 45(5): 497-517

[5] Ni Dong, Duan Jin, Xu Jiucheng. General solutions of FEM ANSYS7.0 examples. Beijing: Electronic Industry Press. 2003, 27-44

[6] Zhang Zhiyong. Master MATLAB6.5 edition course. Beijing: Beijing University of Aeronautics And Astronautics Press, 2003, 1-35 